\title{
Doğrudan Yabancı Yatırımların Türkiye'deki Vergi Gelirleri Üzerindeki Etkisi
}

\author{
Seyhun Tutgun a,
}

\section{Özet}

Bu çalışmada, doğrudan yabancı yatırımların Türkiye'deki vergi gelirleri üzerindeki etkisi incelenmiştir. Çalışmada kullanılan bağımsız değişkenler doğrudan yabancı yatırımlar(DYY), istihdam edilen kişi başı gayrisafiyurtiçihasıla iken bağımlı değişken olarak vergi geliri kullanılmaktadır. Türkiye'ye ait yıllık verilerin kullanıldığ 1 çalışmada 19742016 arasındaki dönem incelenmiştir. Zaman serisi analizinin kullanıldığı çalışmada entegrasyon düzeyini bulmak için ADF ve PP birim kök testlerinden yararlanılmıştır. Çalışmada yer alan değişkenlerin durağanlık düzeyleri farklı olduğu için Pesaranvd'nin (2001) geliştirmiş oldukları ARDL Sınır Testi yaklaşımı kullanılmıştır. Bulgular, hem kısa dönemde hem de uzun dönemde doğrudan yabancı yatırımların vergi gelirlerini pozitif yönde etkilediğini göstermektedir. Bu sonuçtan yola çıkarak Türkiye'nin doğrudan yabancı yatırımları (DYY) arttırmak için politikalar ortaya koymasının vergi gelirlerini arttırabileceği ifade edilebilir.
Anahtar Kelimeler

DYY

Vergi Geliri

ARDL

Durağanlık

Makale Hakkında

Geliş Tarihi: 07.11.2018

Kabul Tarihi: 29.11.2019

Doi: 10.18026/cbayarsos.480146

\section{The Effect of Foreign Direct Investment on Tax Revenues in Turkey}

\begin{abstract}
In this study, the effect on tax revenues of foreign direct investments in Turkey was examined. While the independent variables used in the study are foreign direct investments (FDI), the gross domestic product per capita employed, tax income is used as the dependent variable. In this study, the annual data of Turkey was used and the period between 1974-2016 was examined. ADF and PP unit root tests were used to find the integration level in the study in which time series analysis was employed. Since the stationarity levels of the variables in the study were different, Pesaran et al. (2001) developed ARDL Boundary Test approach. The findings show that both foreign direct investments have positive effects on tax revenues both in the short term and long term. Based on this result, it can be said that tax revenues can be increased through Turkey's foreign direct investment (FDI).
\end{abstract}

Keywords

FDI

Tax Revenue

ARDL

Stationarity

About Article

Received: 07.11.2018

Accepted: 29.11.2019

Doi: $10.18026 /$ cbayarsos.480146

a İletişim Yazarı: stutgun@beu.edu.tr

b Öğr. Görevlisi, Bitlis Eren Üniversitesi Hizan Meslek Yüksekokulu, Finans, Bankacılık ve Sigortacılık Bölümü, ORCID: 0000-0001-7328-1294 


\section{Giriş}

Geçmişten günümüze devletler temel görevlerini yerine getirmek için bir gelire ihtiyaç duymuştur. Bu geliri sağlamak için kullanılan en önemli kaynak ise vergi olmuştur. Verginin tanımına geçmeden önce ne kadar vazgeçilmez bir kavram olduğunu Benjamin Franklin 1789' da Jan Baptiste Le Roy'a yazdığı bir mektupta şöyle ifade etmiştir: “Bu dünyada hiçbir şeyden emin olamazsın ölüm ve vergiden hariç." Vergi, kaçınılması mümkün olmayan ve tarih boyunca bütün iktidarların kullanmış olduğu bir araçtır.

Vergiler, devletin veya devlet tarafından vergilendirme yetkisi verilen diğer kamu tüzel kişilerin hukuki bir dayanakla yasal ve karşılıksız olarak aldıkları ekonomik değerlere denir (Güler ve Karaca, 2017: 165). Vergi, başka bir tanıma göre kamu hizmetlerinin maliyetini karşılamak üzere karşılıksız olarak devlete kaynak aktarılmasıdır. Kısaca devletin vatandaşlarına karşı borçlanması olarak tanımlanabilir. Bu borçlanma karşılığında devlet, vatandaşlarına karşı olan sorumluluklarını yerine getirip refah düzeyinin arttırılması açısından bazı adımlar atmaktadır.

Genel olarak literatürde vergiler doğrudan ve dolaylı vergiler olmak üzere iki başlık altında incelenmektedir. Dolaysız vergiler, vergi mükellefi ile bu vergiyi ödeyen kişinin aynı olduğu, gelir düzeyine göre alınan vergilerdir (Temiz, 2008: 3). Bu vergi türünde verginin mükellefi, üzerine düşen vergi sorumluluğunu başkasına aktaramaz. Gelirvergisi, motorlu taşıtlar vergisi, kurumlar vergisi dolaysız ya da doğrudan vergi türüne örnek gösterilebilir. Dolaylı vergiler ise vergi mükellefi ile ödeyicisinin farklı olduğu (Temiz, 2008:3), tüketim üzerinden alınan vergilerdir (Durkaya ve Ceylan, 2006: 80). Dolaylı vergilere örnek olarak özel tüketim vergisi ve KDV gösterilebilir. Ülkelerin gelişmişlik düzeylerine göre bu vergilerin toplam vergi tutarı içindeki payları farklılık göstermektedir. Gelişmekte olan ülkelerde dolaylı vergiler ağırlıkta iken gelişmiş ülkelerdeki sanayileşme, kişi başına düşen gelirin artması gibi faktörler dolaysız vergilerin ağırlığını arttırmaktadır (Mutlu ve Çelen, 2012: 13).

Bir ekonominin sürdürülebilir ve hızlı ekonomik büyümesi, yatırımların büyüklügüne ve oranına önemli ölçüde bağlıdır. Bu, hem yurt içi hem de yurt dışı yatırımlarda, artan sermaye miktarları ve teknolojideki değişimlerle birlikte genellikle büyük yatırımlar gerektirir. Bununla birlikte, Türkiye dâhil olmak üzere birçok gelişmekte olan ekonominin tasarrufları ve yatırımları arasında büyük bir uçuruma yol açacak şekilde düşük yerel tasarruf seviyeleri bulunmaktadır. Aslında, Türkiye' de tasarruf ve yatırım dengesinde, uzun zamandır tasarruf aleyhine açık söz konusudur; bu nedenle ülkeye büyük sermaye akışları gerekmektedir. Bu sermaye akışı doğrudan yabancı yatırımlarının (DYY) girişi ile mümkün olabilmektedir. DYY, ev sahibi ekonomi için potansiyel olarak verimlilik artışı sağlayacağından, bir büyüme motoru olarak kabul edilir. Ayrıca yatırım hacmini ve verimliliğini arttırmak, mevcut bilgi birikimini genişletmekte, lider teknolojiye erişimi kolaylaştırmakta, yeni yerel tedarikçilerin zincirlerini oluşturmakta ve yeni pazarlara erişim açmayı kolaylaştırmaktadır (Jeza, vd. 2016: 1). Sonuç olarak; son yıllarda, çok çeşitli vergi teşvikleri sunarak ülkeler arasında DYY çekmeye yönelik rekabet artmaktadır (IMF, 2006).

Bu çalışma, daha önce farklı ülkeler üzerinde yapılan DYY ve vergi gelirleri arasındaki ilişkiyi Türkiye özelinde ele almaktadır. Çalışma beş bölümden oluşmaktadır; ilk bölümde konu hakkında genel bilgilerin yer aldığı giriş bölümü, ikinci bölümde literatürde daha önce yapılmış çalışmaların yer aldığı literatür bölümü, üçüncü bölümde kullanılacak yöntemin ye 
aldığ1 veriler hakkındaki model ve veri seti bölümü, dördüncü bölümde çalışmadaki bulguların yer aldığı ekonometrik sonuçlara yer verilirken beşinci ve son bölümde ise sonuç ve öneriler kısmı bulunmaktadır.

\section{Literatür}

DYY genel olarak bir ülkede gelir seviyesi ve ekonomik büyüme üzerinde olumlu bir etkiye sahiptir. Bu da bir ülkede dolaylı vergi gelirinin artmasına yardımcı olarak ekonomik faaliyetlerin ve toplam talebin artmasını sağlayacaktır (Mahmood ve Chaudhary, 2013: 60). Bu açıdan bakıldığında Türk vergi sistemi de dolaylı vergilerin ağırlıkta olduğu bir yapıya sahiptir (Mutlu ve Çelen, 2012: 13). Bu yüzden DYY'nin Türkiye'deki vergi gelirlerini arttırıcı bir etkisi olduğu söylenebilir. Literatürde gelişmekte olan ülkelerin DYY çekmek için vergi indirimlerini kullanmaları gerektiği üzerinde durulmuştur. Arz yönlü iktisat olarak da isimlendirilen bu süreç Haldun-Laffer etkisi ile izah edilmektedir. Bu etki vergi indirimlerinin ekonomik birimler üzerinde yapmış olduğu etki ile kararları etkileyip toplam üretimi ve vergi gelirlerini arttıracağını ifade etmektedir (Aktan, 2009: 46).

1980'lerden itibaren küreselleşme süreci ile birlikte dünyadaki doğrudan yabancı yatırım girişlerinin akışında önemli artışlar olmuştur. Doğrudan yabancı yatırımlar dolaylı yoldan vergi gelirlerinde artışlara neden olmuştur. Bu düşünceye paralel olarak literatürde DYY ve vergi gelirleri arasındaki pozitif ilişkinin yer aldığı çalışmalar bulunmaktadır. Bu çalışmalarla birlikte DYY ve vergi gelirleri arasındaki nedensellik ilişkisini açıklayan çalışmalar da aşağıda kısaca özetlenmiştir.

Bond ve Samuelson (1986), ev sahibi ülkede kısa vadede DYY çekilmesi için vergi tatilleri verildiği takdirde kısa vadede vergi gelirlerinin kaybolacağını ifade etmişlerdir. Uzun vadede ise yabancı yatırımcının çekilmeyeceğini böylece vergi gelirlerinin artabileceğini ifade etmişlerdir. Brander ve Spencer (1987), ev sahibi ülkelerin ithalata tarife uygulayarak ve yerel üretim vergisini esneterek DYY çekebileceğini belirtmişlerdir. DYY'nin işsizliği azaltma, teknoloji transferleri yoluyla üretkenliği arttırma ve vergilendirme yoluyla devlet gelirini yükseltme etkisinin ulusal refahı artırabileceğini belirtmişlerdir. Horstmann ve Markusen (1987), hükûmet gelirleri, tüketim artışındaki değişim ve ticaret politikası yoluyla refah etkisini analiz etmişlerdir. Ev sahibi ülkenin hükûmetinin ithalat vergisi uygulayabileceğini ve yabancı yatırımcıları vergiden muaf tutabileceğini ifade etmişlerdir. Vergi tarifesi hükûmetin gelirini artırdığı için, vergi imtiyazı ile yabancı yatırımdan daha iyi bir refah etkisi oluşabileceği vurgulanmıştır. Dunning (1992), ev sahibi ülkedeki DYY'nin refah etkilerinin, yabancı yatırımcılarla ev sahibi ülkenin pazarlık gücüne bağlı olduğunu, bu ülkelerde yabancı yatırımları çekmek için enerji iadesi veya işgücü maliyetine vergi indirimi teklif ettiğini gözlemlemiştir.Raff ve Srinivasan (1998), hükûmetin yabancı yatırımları çekmek için bazı vergi gelirlerinden feragat etmesi gerektiğini çünkü DYY'nin, istihdam yaratacağını, yerel emeğin eğitilmesini sağlayacağını, teknoloji transferini arttıracağını ve daha iyi yönetim becerileri kazandıracağını iddia etmiştir. Mudambi (1999), ülkelerin uygun bölgelerdeki uygun tipte yabancı yatırımı seçerek refahı artırabileceğini ve geri kalmış alanlarda yaşam standartlarının yükseltilmesine yardımcı olacak vergi gelirleri sağlayabileceğini iddia etmiştir. Markusen (2001), refah etkilerini DYY, ihracat ve lisanslama arasında bir seçim ile modellemiş ve DYY'nin diğer değişkenlere göre refah sağlayıcı etkisinin ev sahibi ülke için en yüksek olduğunu bulmuştur. Markusen'in Bilgi-Sermaye Modeli'nde, yüksek ticari maliyeti ile 
birlikte DYY'nin, kalifiye emek bol olan ülkeler için refahı pozitif yönde arttırıcı bir etkisi olduğu bulunmuştur. DYY'nin refah etkisi, büyük ülkeler için ve düşük işlem maliyeti olan vasıflı işgücü bol olan ülkeler için de pozitif olmuştur (Markusen vd.1996; Markusen 1997; Markusen 2002). Nguyen vd. (2013) DYY'nin bir ülkede refah üzerindeki etkisini inceledikleri çalışmada, yapılacak yatırımları etkileyen faktörler incelenmiştir. DYY'nin devlet gelirleri üzerindeki etkisinin rekabet etkisine ve teknolojik yayılmalara bağlı olacağı sonucuna ulaşılmıştır. Rekabet etkisinin, yerli firmaların üretimini azalttığını ve dolayısıyla kurumlar vergisi gelirini düşürdüğü teknolojik yayılmaların ise yerel firmaların emilim kapasitesine bağlı olarak olumlu veya olumsuz refah etkilerine sahip olabileceği ifade edilmiştir. DYY'nin ev sahibi ülkede devlet gelirine olan katkısının, talep yaratma etkisine ve teknolojik transfer maliyetine de bağlı olduğunu vurgulamıştır. Kısacası çalışmanın sonuçlarına göre DYY'nin vergi gelirleri üzerindeki etkisinin, rekabet etkisi, talep yaratma etkileri, teknoloji transfer maliyeti ve teknolojik yayılmalara bağlı olduğu sonucuna ulaşılmıştır.

Caves (1971), yabancı yatırımın, kurumlar vergisi tahsilatı yoluyla refahın olumlu bir etkisi olduğunu iddia etmiştir. DYY'nin, ev sahibi ülkede vergi gelirlerindeki artışla genel refahı arttırabileceğini vurgulamıştır. Bir ülkenin refahı, yabancı yatırımların vergisinde indirim ya da yabancı firmaların kendi ülkelerindeki transfer fiyatlaması üzerinden yapılırsa azalır (Kopits, 1976). Markusen (1984), DYY'nin refah etkisinin belirsiz olduğunu iddia etmiştir. Yabancı yatırımlar, yerel işletmeler tarafından kazanılan kârların yabancı şirketlere aktarılması yoluyla kârlılıkta rekabet ve vergi artışıla refahı attırmaktadır. Skeie (2017) tarafından yapılan çalışmada ise ÇUŞ’ün kurumsal vergi sistemindeki uluslararası farklılıklara cevabı nedeniyle ülkeler arasında DYY ve vergi gelirlerinin yeniden dağılımı değerlendirilmiştir. Çalışma, DYY'nin vergi duyarlılığı ile ilgili literatürü kısaca gözden geçirmekte ve bu oranın, vergi oranı farklılıklarının yokluğunda, iki taraflı DYY pozisyonlarını hesaplamak için iki taraflı DYY verileriyle birlikte, bu duyarlılı̆̆ın ortak bir tahminini kullanmaktadır. İkinci adımda, vergi gelirleri, geleneksel bir yatırım getirisi oranı varsayılarak tahmin edilmiştir. Çoğu OECD ülkesinde, vergi oranı farklarının DYY pozisyonların $\%$-15 ile \% 15'i arasında değiştirdiği ifade edilmiştir. DYY üzerindeki vergilerin hesaplanan etkileri, gerçek yatırımları, vergi planlama davranışlarını ve metodolojiyi yansıttığı vurgulanmıştır. Ayrıca çalışmada metodolojinin, ÇUŞ’ün vergi planlama faaliyetlerinin sadece bir kısmını tuttuğuna, çünkü bu faaliyetlerin bir kısmı DYY pozisyonlarının büyüklüğüne yansıtılmadığına da değinilmiştir. Kimm Gnangnon (2017), 172 ülke üzerinde yapmış olduğu çalışmada 1980-2013 dönemini incelemiştir. İncelenen dönemde DYY girişinin, devlet geliri, özellikle toplam kaynak dışı vergi geliri ve kaynak dışı kurumlar vergisi geliri üzerindeki etkisini incelemiştir. Sonuçlar DYY girişlerinin bu iki hükûmet gelirinin her biri üzerindeki etkisinin, ev sahibi ülkelerin Gayri Safi Yurtiçi Hasıla (GSYİH) yüzdesiyle ifade edilen DYY girişlerinin seviyesine bağlı olduğunu göstermektedir.

Gropp ve Kostial (2000), DYY ve vergi geliri arasındaki ilişkiyi bulmak için 19 OECD ülkesi üzerinde panel veri analizi yöntemini kullanmıştır. Çalışmanın sonuçlarına göre DYY ile kurumlar vergisi arasında zayıf bir korelasyon bulunmuştur. Ayrıca DYY girişlerinin toplam vergi gelirlerini pozitif ve güçlü bir şekilde etkilediği sonucuna ulaşılmıştır. Mahmood ve Chaudhary (2013) tarafından Pakistan üzerinde yapılan çalışmada da DYY'nin vergi gelirleri üzerindeki etkisi analiz edilmiştir. Çalışma ARDL Sınır Testi yaklaşımı kullanılarak 1972-2010 aralığında yapılmış ayrıca yıllık veriler kullanılmıştır. Çalışmada bağımlı değişken vergi geliri, bağımsız değişkenler ise DYY ve istihdam edilen başına düşen millî gelirdir. Bulgulara 
göre kısa ve uzun dönemde DYY ve istihdam edilen başına düşen millî gelirin vergi gelirleri üzerinde pozitif ve önemli bir etkisi olduğu sonucuna ulaşılmıştır. DYY'nin, Pakistan'da vergi gelirlerini arttırıcı bir etkisi olduğu bulunmuştur. Odabas (2015) çalışmasında, 1996-2012 döneminde doğrudan yabancı sermaye girişlerinin Avrupa Birliği'nin Bulgaristan, Hırvatistan, Çek Cumhuriyeti, Estonya, Macaristan, Letonya ve Slovenya dâhil olmak üzere seçilmiş geçiş ekonomilerindeki vergi gelirleri üzerindeki etkisini incelemiştir. Dumitrescu ve Hurlin (2012) nedensellik testini kullanarak yapmış olduğu çalışmada doğrudan yabancı yatırım net girişlerinden vergi gelirlerine tek yönlü nedensellik olduğunu ve doğrudan yabancı yatırım net girişlerinden ekonomik büyümeye kadar tek yönlü nedensellik olduğu sonucunu dile getirmiştir. Jeza, vd. (2016) Etiyopya'da DYY ve vergi gelirleri arasındaki ilişkiyi 1974-2014 aralığında ele almışlardır. Çalışmada vergi, kurumlar, gelir, ticari ve iş kârı vergisi olarak ayrı ayrı ve toplam vergi gelirleri olarak kullanılmış ve ARDL Sınır Testi yaklaşımıyla incelenmiştir. Analiz sonuçlarına göre kısa ve uzun dönemde hem DYY'nin hem de millî gelirin vergi gelirlerini negatif yönde etkilediği ortaya konulmuştur. Çalışmanın sonuçlarına göre araştırmacılar vergi teşviklerinin Etiyopya'da dikkatle değerlendirilmesinin ve izlenmesinin gerektiğini ifade etmişlerdir. Ayrıca bu teşviklerle ilgili maliyetlerin ve elde edilen verimliliğin değerlendirilip uygun bir politikanın geliştirilmesi gerektiğini ifade etmişlerdir. Son olarak izleme ve değerlendirme sisteminin, vergi gelirlerini artıracak şekilde geliştirilmesi ve uygulanması gerektiğine dikkat çekmişlerdir. 1989-2009 yılları arasında DYY ve vergi gelirleri arasındaki ilişkiyi farklı boyutlardan ele alan Okey (2013) vergi gelirlerini sektörel açıdan da incelemiştir. Sekiz Batı Afrika ülkesi üzerinde yapılan panel veri analizi sonuçları şu şekildedir: İlk olarak DYY pozitif yönde ve önemli ölçüde vergi gelirlerini etkilemektedir. Özellikle gelir ve kâr üzerinden alınan vergileri etkilemektedir. İkincisi, toplam vergi gelirleri, gelir ve kârlar üzerindeki vergi için, tarım sektörüne tahsis edilen DYY, sanayi ve madencilik sektörlerine tahsis edilen DYY'den daha az zararlıdır. Ayrıca, sadece sanayi ve madencilik sektörüne tahsis edilen DYY, uluslararası ticaret vergileriyle önemli ölçüde bağlantılıdır. Demokrasi ve düşük yolsuzluk düzeyi, DYY'nin vergi gelirleri, özellikle de uluslararası ticaret vergileri üzerinde uyguladığı olumlu etkiyi güçlendirmektedir. Son olarak, kalkınma, enflasyon, dış ticaret açığı, dış yardım ve eğitim gibi diğer faktörler millı̂ geliri önemli ölçüde etkilemektedir.

Sarısoy ve Koç (2010), 21 OECD ülkesi üzerine yaptıkları çalışmada 1981-2008 yılı verilerini kullanarak DYSY'nin bu ülkelerdeki kurumlar vergisi hasılatına etkisini incelemişlerdir. Panel regresyon yöntemi kullanılarak yapılan çalışmada DYSY yapıldıktan 1-2 yıl sonra kurumlar vergisi hasılatını arttırdığı bulunmuştur. İncelenen ülkeler arasında Norveç kurumlar vergisi hasılatının en çok arttı̆̆ ülke iken en az artış gösteren ülke Türkiye olarak bulunmuştur. Bu farklılığın sebebi olarak vergi oranları, harcamalar vb. faktörler gösterilmiştir. Türkiye üzerine yapılan diğer bir çalışmada Koşar ve Van (2012), 2000-2011 yılları arasında aylık veriler kullanarak yapmışlardır. Bu çalışmada kurumlar vergisi oranındaki düşüşlerin vergi hasılatına etkisi, toplam vergi içerisindeki kurumlar vergisi payı, yabancı firma sayısı ve DYSY girişi arasındaki ilişki incelenmiştir. Çalışmanın sonucuna göre Türkiye'de kurumlar vergisi oranı ile DYSY arasındaki ilişkinin ters yönlü olduğu ifade edilmiştir. Balıkçıŏlu vd. (2016) Türkiye üzerine yapmış oldukları çalışmada 2004-2012 dönemine ait Türk imalat firmalarına ait bir veri seti kullanmışlardır. DYY'nin Türkiye'de ödenen vergiler üzerindeki etkisini, farklı teknoloji düzeylerinde faaliyet gösteren firmalar arasındaki farklılıkları incelemişlerdir. Çalışmanın sonuçlarına göre yabancı ortaklıklar firmaların ödediği vergileri arttırmaktadır. 
Ayrıca orta ve düşük teknolojili firmalardan yüksek teknolojili firmalara vergilendirme konusunda DYY'nin daha büyük bir etkisi olduğu sonucuna ulaşılmıştır. DYY ve vergi gelirleri arasındaki ilişkiyi AB üyesi ülkeler ve Türkiye üzerine inceleyen Bahtiyar, Karabacak ve Meçik (2018), 1989-2016 dönemini incelemişlerdir. Granger nedensellik ilişkisi için Konya (2006) panel nedensellik testini kullanmışlardır. Analiz sonuçları DYY'den toplam vergi gelirlerine doğru bir nedenselliğin olduğu ülkelerin İrlanda ve İspanya olduğu şeklinde iken DYY'den sadece kurumlar vergisine nedensellik ilişkisinin olduğu ülkelerin Almanya ve Portekiz olduğu şeklindedir. Geriye kalan ülkelerde DYY ve vergi gelirleri arasında herhangi bir nedensellik ilişkisi olmadığı sonucuna ulaşılmıştır.

Andrejovska ve Pulikova (2018), çalışmalarında DYY'nin içinde yer aldığı bazı makroekonomik göstergelerin toplam vergi geliri üzerindeki etkisini ölçmeyi amaçlamışlardır. $28 \mathrm{AB}$ üyesi ülke üzerindeki çalışmalarında havuzlama modeli, sabit etkiler modeli ve rastgele etkiler modeli olarak farklı regresyon analiz modelleri kullanmışlardır. Bu makro ekonomik değişkenler arasındaki en güçlü korelasyon vergi gelirleri ve istihdam arasındaki iken devamındaki değişkenler GSYİH ve DYY olarak bulunmuştur. DYY'de meydana gelecek bir birimlik artışın vergi gelirlerini 434,2 bin € arttıracağ 1 ifade edilmektedir. Literatürde yer alan en güncel çalışmalardan biri Basheer, Ahmad ve Hassan (2019) tarafından yapılmıştır. Ekonomik ve finansal faktörlerin vergi gelirleri üzerindeki etkisi incelenmiştir. Bahreyn ve Umman üzerine yapılan 1990-2010 dönemini kapsayan çalışmada panel regresyon analizi kullanılmıştır. Çalışmadaki analiz sonuçları vergi gelirlerinin hem ekonomik hem de finansal faktörler ile arasında anlamlı bir ilişki olduğu yönündedir. Fakat GSYİH'deki büyüme, DYY net girişi ve nakit fazlası / açık gibi faktörlerin diğer finansal değişkenlere göre vergi gelirlerini daha fazla etkilediği sonucuna ulaşılmıştır.

Literatürde yapılan çalışmaları kısaca özetlemek gerekirse DYY vergi gelirlerini genel olarak arttıran bir faktördür. Bu vergi gelirlerini kurumlar vergisi yoluyla daha çok arttırmaktadır. Ayrıca ülkedeki kurumlar vergisinin oranı, vergi teşvikleri ve muafiyeti DYY'den elde edilen vergi hasılatını etkileyen diğer faktörler olarak yer almaktadır. Diğer bir önemli konu ise bu değişkenler arasındaki nedensellik ilişkisidir. Genel olarak bu değişkenlerden DYY'den vergi gelirlerine doğru bir nedensellik ilişkisi söz konusu iken Türkiye üzerine yapılan çalışmada (Bahtiyar, Karabacak ve Meçik, 2018) bu ilişki bulunamamıştır.

\section{Yöntem}

Bu çalışmada kullanılan zaman serisi analizinde değişkenlerin durağanlık derecelerini ölçmek adına ADF ve PP birim kök testleri kullanılmıştır. Bu testlerin yapılmasındaki temel amaç zaman serilerinde değişkenlerin durağan olmamasının bazı sorunlar ortaya çıkarabileceğidir. Granger ve Newbold (1974) tarafından da ifade edildiği gibi eğer durağan olmayan seriler kullanılırsa sahte regresyon sorunu ortaya çıkabilir. Sahte regresyon sorunu da ekonometrik analiz sonuçlarının doğruluğunu tehlikeye atacaktır. Bu açıdan, farklı düzeyde durağan olan serilerin (2. dereceden olmamak koşuluyla) bir arada olabileceği ve bunun için uygun bir eşbütünleşme analizine başvurulmuştur (Eriçok ve Yılanc1, 2013:95). Farklı durağanlık seviyesine sahip (2. dereceden olmamak koşuluyla) değişkenler arasındaki uzun dönem ilişkiyi ölçmek için bu çalışmada Pesaran vd.(2001) geliştirmiş oldukları ARDL Sınır Testi yaklaşımı kullanılmıştır. Bu testin diğer eşbütünleşme testlerinden bazı avantajları bulunmaktadır. ARDL 2. dereceden olamamak koşuluyla farklı durağanlık seviyesine sahip değişkenler arasındaki uzun dönem ilişkiyi inceleyebilmektedir. Bu testin diğer bir avantajı 
ise az sayıda gözlemle sağlıklı sonuçlara ulaşılabilmesidir (Şimşek ve Kadılar, 2005: 146). ARDL Sınır Testi yaklaşımı iki aşamadan oluşmaktadır: ilk aşamada uzun dönem ilişkinin varlığı test edilir, ikinci aşamada değişkenlere ait uzun ve kısa dönem tahminleme yapılır.

\section{Model ve Veri Seti}

DYY'nin vergi gelirleri üzerindeki etkisini ölçmek için vergi gelirlerinin millî gelire (GSYİH) oranı bağımlı değişken olarak kullanılmıştır. Bağımsız değişkenler ise istihdam edilen kişi başına düşen GSYİH ve GSYİH'nin yüzdesi olarak DYY değişkenleri kullanılmıştır.

Çalışmada kullanılan model ve değişkenler şu şekildedir;

$$
\begin{aligned}
& \mathrm{T}_{\mathrm{t}}=\mathrm{f}\left(\mathrm{DYY} \mathrm{Y}_{\mathrm{t}}, \mathrm{P}_{\mathrm{t}}\right) \\
& \mathrm{T}_{\mathrm{t}}=\mathrm{GSYH} \text { nin yüzdesi olarak vergi gelirleri } \\
& \mathrm{DYY}=\mathrm{DY} Y^{\prime} \text { nin GSYİH'ye olan oranı } \\
& \mathrm{Pt}=\text { İstihdam edilen kişi başına düşen GSYİH } \\
& \mathrm{T}=\beta_{0}+\beta_{1} \mathrm{DYY}+\beta_{2} \mathrm{P}
\end{aligned}
$$

Çalışmada Türkiye'ye ait 1974-2016 yıllarına ait yıllık veriler kullanılmıştır. Vergi gelirlerinin GSYH'ye oranı OECD veri tabanından, DYY'nin GSYİH'ye olan oranına ait verileri Dünya Bankası veri tabanından ve istihdam edilen kişi başına düşen GSYH verisi de OECD veri tabanından elde edilmiştir. Çalışmada Eviews 9 paket programı kullanılmıştır.

\begin{tabular}{|c|c|c|c|c|}
\hline \multicolumn{2}{|c|}{ DÜZEY } & $\mathrm{T}$ & DYY & $\mathbf{P}$ \\
\hline \multirow{3}{*}{$\mathrm{ADF}$} & Sabit & $-1.2130(0)$ & $-1.7473(0)$ & $-0.7334(0)$ \\
\hline & Sabit+trend & $-1.7998(0)$ & $-4.5702^{* * *}(0)$ & $-3.5177^{*}(0)$ \\
\hline & Sabit & $-1.2129(9)$ & $-1.4585(4)$ & $-0.7334(5)$ \\
\hline PP & Sabit+trend & $-1.8844(4)$ & $-4.5121^{* * *}(1)$ & $-3.5966^{* *}(2)$ \\
\hline \multicolumn{5}{|c|}{ BİRINCI FARKLAR } \\
\hline \multirow{3}{*}{$\mathrm{ADF}$} & Sabit & $-5.7209^{* * *}(0)$ & $-9.1375^{* * *}(0)$ & $-7.8213^{* * *}(0)$ \\
\hline & Sabit+trend & $-5.6375^{* * *}(0)$ & $-9.0498^{* * *}(0)$ & $-7.7212^{* * *}(0)$ \\
\hline & Sabit & $-5.8417^{* * *}(15)$ & $-9.9304^{* * *}(7)$ & $-7.9098^{* * *}(2)$ \\
\hline PP & Sabit+trend & $-5.7337^{* * *}(15)$ & $-9.7043^{* * *}(7)$ & $-7.8020^{* * *}(2)$ \\
\hline \multicolumn{2}{|c|}{ SONUC } & $\mathrm{I}(\mathbf{1})$ & $\mathrm{I}(0)$ & $\mathrm{I}(0)$ \\
\hline
\end{tabular}

\section{Bulgular}

Bu bölümde değişkenlerin durağanlık analizleri ADF ve PP birim kök testleriyle incelenmiştir. Yapılan analiz sonuçlarına göre ADF ve PP test sonuçları Tablo 1'de verilmiştir.

Tablo 1: ADF ve PP Durağanlık Testi Sonuçları

(1) Parantez içindeki değerler AIC kullanılarak seçilen gecikme uzunluklarıdır.

(2) ${ }^{* * *},{ }^{* *}$ ve * ilgili değişkenlerin sırasıyla \%1, \%5 ve \%10 düzeyinde durağan olduklarını göstermektedir

Analiz sonuçlarına göre DYY ve $\mathrm{P}$ değişkeninin düzeyde [I(0)] durağan oldukları görülmektedir. T değişkeni incelendiğinde hem ADF hem PP birim kök test sonuçlarına göre düzeyde durağan olmadığı görülmektedir. T değişkeni birinci farkta [I(1)] durağan hâle gelmektedir. Farklı durağanlık düzeylerine sahip değişkenler arasındaki uzun dönem ilişkiyi incelemek adına ARDL Sınır Testi yaklaşımı kullanılmıştır. Bu testin ilk aşaması değişkenler arasında eşbütünleşme ilişkisi olup olmadığıdır. Eşbütünleşme ilişkisinin incelendiği analiz sonuçları Tablo 2' de yer almaktadır. 
Tablo 2: Uzun Dönem Eşbütünleşme İlişkisinin Test Sonuçları

\begin{tabular}{|l|l|l|l|}
\hline \multicolumn{4}{|l|}{ Model: T (T IDYY, P) } \\
\hline F- istatistik & Gecikme Uzunluğu & Alt-Üst Sınır Değer & Eşbütünleşme ilişkisi \\
\hline 5.51 & 8 & $4.01-5.07$ & Var \\
\hline
\end{tabular}

(1) Maksimum gecikme uzunluğu olarak 8 alınmış ve en uygun gecikme uzunluğunun belirlenmesinde AIC

(Akaike İnformation Criteria) kullanılmıştır.

(2) \%5 anlamlılık düzeyinde alt ve üst kritik sınır değerleri Pesaranvd(2001)'den alınmıştır.

(3) Modelde trend kullanılmıştır.

$$
\begin{array}{ll}
H_{0}: \beta_{1}=\beta_{2}=\beta_{3}=0 & \text { (Eşbütünleşme ilişkisi yok) } \\
H_{1}: \beta_{1} \neq \beta_{2} \neq \beta_{3} \neq 0 & \text { (Eşbütünleşme ilişkisi var) }
\end{array}
$$

Tablo 2'deki sonuçlarına göre değişkenler arasında eşbütünleşme ilişkisi olup olmadığına bakıldığında F-istatistik değeri baz alınmaktadır. F-istatistik değeri ve Pesaran vd. (2001) vermiş oldukları tablo değerlerinin alt-üst sınır değeri (4.01-5.07) karşılaştırılmaktadır. Değişkenlerden birinin birinci farkta [I(1)] diğer iki değişkenin düzeyde [(0)] durağan olmasından dolayı F-istatistik değeri üst sınır değerine göre incelenecektir. Sonuçlara göre Fistatistik değeri (5.51) tabloda da belirtilen üst sınır değerden (5.07) büyük olduğu için kurulan boş (null) hipotezi reddedilir. Bu da modelde yer alan değişkenler arasında eşbütünleşme ilişkisi olduğunu yani uzun dönemde ilişki olduğunu ifade etmektedir. Bu ilişkinin varlığı bulunduktan sonra değişkenler arasındaki kısa ve uzun dönem model tahminlemesi yapılması gereklidir. Tahmin sonuçları bu modelin ARDL $(3,8,5)$ şeklinde olması gerektiği yönündedir. Modelin tahmin sonuçlarının ve katsayıların yer aldığı tablo aşağıda verilmiştir (Tablo 3).

Tablo 3: ARDL Modelinin Tahmin Sonuçları

Model: FT (TI DYY, P)

Model Spesifikasyonu: ARDL(3,8,5)

Bağımlı Değişken: T

\begin{tabular}{|c|l|l|l|}
\hline Değişkenler & Katsayı & Standart Hata & t-istatistiği \\
\hline $\mathrm{T}_{(-1)}$ & 1.0046 & 0.1991 & $5.0443[0.000]^{* * *}$ \\
\hline $\mathrm{T}_{(-2)}$ & -0.3726 & 0.3101 & $-1.2016[0.248]$ \\
\hline $\mathrm{T}_{(-3)}$ & -0.5099 & 0.2841 & $-1.7943[0.092]^{*}$ \\
\hline $\mathrm{DY}$ & 0.0637 & 0.0282 & $2.2554[0.039]^{* *}$ \\
\hline $\mathrm{DYY}_{(-1)}$ & 0.0229 & 0.0243 & $0.9430[0.360]$ \\
\hline $\mathrm{DYY}_{(-2)}$ & 0.0512 & 0.0207 & $2.4664[0.026]^{* *}$ \\
\hline $\mathrm{DYY}_{(-3)}$ & 0.0062 & 0.0212 & $0.2936[0.773]$ \\
\hline $\mathrm{DY}_{(-4)}$ & 0.0569 & 0.0197 & $2.8794[0.011]^{* *}$ \\
\hline $\mathrm{DYY}_{(-5)}$ & 0.0098 & 0.0211 & $0.4641[0.649]$ \\
\hline $\mathrm{DYY}_{(-6)}$ & 0.0046 & 0.0167 & $0.2738[0.787]$ \\
\hline $\mathrm{DY} Y_{(-7)}$ & 0.0157 & 0.0153 & $1.0248[0.321]$ \\
\hline $\mathrm{DYY}_{(-8)}$ & 0.0392 & 0.0177 & $2.2150[0.042]^{* *}$ \\
\hline $\mathrm{P}$ & -0.7718 & 0.2883 & $-2.6762[0.017]^{* *}$ \\
\hline $\mathrm{P}_{(-1)}$ & -0.8562 & 0.3505 & $-2.4424[0.027]^{* *}$ \\
\hline $\mathrm{P}_{(-2)}$ & -0.3387 & 0.2498 & $-1.3558[0.195]$ \\
\hline $\mathrm{P}_{(-3)}$ & 0.0099 & 0.2601 & $0.0383[0.969]$ \\
\hline
\end{tabular}




\begin{tabular}{|l|l|l|l|}
\hline $\mathrm{P}_{(-4)}$ & -0.6512 & 0.3005 & $-2.1670[0.046]^{* *}$ \\
\hline $\mathrm{P}_{(-5)}$ & -0.7809 & 0.2947 & $-2.6496[0.018]^{* *}$ \\
\hline Sabit & 11.035 & 3.0184 & $3.6559[0.002]^{* * *}$ \\
\hline Trend & 0.0880 & 0.0277 & $3.1776[0.006]^{* * *}$ \\
\hline Tanısal Testler & 0.987 \\
\hline \multicolumn{2}{|l|}{$\mathrm{R}^{2}$} & 0.971 \\
\hline Düzeltilmiş-R ${ }^{*+*}$ & $61.256(0.000)$ \\
\hline F-istatistiği & $1.671(0.226)$ \\
\hline Breusch-Godfrey LM Otokorelasyon Testi & $1.727(0.143)$ \\
\hline White Değişen Varyans Testi & $0.919(0.382)$ \\
\hline Jarque-Bera Normallik Testi & $0.001(0.969)$ \\
\hline Ramsey-Reset Testi &
\end{tabular}

(1) ARDL modelinde gecikme sayısı AIC'ye göre 8 olarak belirlenmiştir.

(2) Parantez içindeki rakamlar p-olasılık değerlerini göstermektedir. ${ }^{* * * * *}$ ve ${ }^{*}$ sırasıyla $\% 1, \% 5$ ve $\% 10$ düzeylerinde anlamlılıklarını gösterir.

Çalışmada yapılan tahmin sonuçlarındaki tanısal testler (Breusch-Godfrey LM Otokorelasyon Testi, White Değişen Varyans Testi,Jarque-Bera Normallik Testi, Ramsey-Reset Testi) Tablo 5.3 'te verilmiştir. $\mathrm{Bu}$ tanısal testlerin sonuçlarına bakıldığında modelde \%5 anlamlılık düzeyinde otokorelasyon(0.226), değişen varyans(0.143) sorununa rastlanmamıştır. Ayrica Jarque-Bera test sonucuna(0.382) göre hata terimlerini normal dağıldığı görülmektedir. Ramsey-Reset sonuçları ise herhangi bir model kurma hatasının olmadığı yönündedir. Modelin açıklama gücünün yüksek (0.98) ve bütün olarak anlamlı olduğu görülmektedir. ARDL $(3,8,5)$ modeline ait uzun ve kısa döneme ait ilişkinin tahmin edildiği sonuçlar Tablo 4 ve Tablo 5 'te yer almaktadir.

Tablo 4: ARDL Uzun Dönemi Tahmin Sonuçları

\begin{tabular}{|c|c|c|c|}
\hline Model: $\mathrm{F}_{\mathrm{T}}(\mathrm{T} \mid \mathrm{DYY}$ & & & \\
\hline Model Spesifikasy & $\operatorname{RDL}(3,8,5)$ & & \\
\hline Bağımlı Değişken: & & & \\
\hline Değişkenler & Katsayı & Standart Hata & t-istatistiği \\
\hline DYY & 0.3081 & 0.0755 & $4.0794[0.001]^{* * * *}$ \\
\hline $\mathrm{P}$ & -3.8602 & 0.5026 & $-7.6798[0.000]^{* * * *}$ \\
\hline Sabit & 12.5690 & 1.3756 & $9.1368[0.000]^{* * *}$ \\
\hline Trend & 0.1003 & 0.0108 & $9.2556[0.000]^{* * *}$ \\
\hline
\end{tabular}

(1) Parantez içindeki rakamlar p-olasılık değerlerini göstermektedir.

(2) ${ }^{* * * * *}$, ve ${ }^{*}$ sirasıly $\% 1, \% 5$ ve \%10 düzeylerinde anlamlılıklarını gösterir.

ARDL $(3,8,5)^{\prime}$ e ait uzun dönem tahmin sonuçları incelendiğinde değişkenlerin \%5 düzeyinde anlamlı olduğu görülmektedir (Tablo 4). T değişkeni ve DYY değişkeni arasında pozitif (0.308), P değişkeni ile negatif (-3.860) bir ilişki bulunmuştur. Bu sonuçlara göre DYY meydana gelen bir artışın vergi gelirlerini uzun dönemde olumlu yönde arttıracağı söylenebilir. Diğer taraftan istihdam edilen kişi başına GSYİH'de meydana gelecek bir artışın vergi gelirlerini uzun dönemde azaltabileceği görülmektedir. 
Tablo 5: ARDL Kısa Dönem Tahmin Sonuçları

\begin{tabular}{|c|c|c|c|}
\hline \multirow{3}{*}{\multicolumn{4}{|c|}{\begin{tabular}{|l} 
Model: FT (TI DYY, P) \\
Model Spesifikasyonu: ARDL $(3,8,5)$ \\
Bağımlı Değişken: T
\end{tabular}}} \\
\hline & & & \\
\hline & & & \\
\hline Değişkenler & Katsayı & Standart Hata & t-istatistiğ \\
\hline $\mathrm{D}(\mathrm{T})(-1)$ & 0.8826 & 0.2572 & $3.4305[0.003]^{* * *}$ \\
\hline $\mathrm{D}(\mathrm{T})_{(-2)}$ & 0.5099 & 0.2841 & $1.7943[0.092]^{*}$ \\
\hline $\mathrm{D}(\mathrm{DYY})$ & 0.0637 & 0.0282 & $2.2554[0.039]^{* *}$ \\
\hline $\mathrm{D}(\mathrm{DYY})_{(-1)}$ & -0.0512 & 0.0207 & $2.4664[0.026]^{* *}$ \\
\hline $\mathrm{D}(\mathrm{DYY})_{(-2)}$ & -0.0062 & 0.0212 & $0.2936[0.773]$ \\
\hline $\mathrm{D}(\mathrm{DYY})(-3)$ & -0.0569 & 0.0197 & $2.8794[0.011]^{* * *}$ \\
\hline $\mathrm{D}(\mathrm{DYY})_{(-4)}$ & -0.0098 & 0.0211 & 0.4641 [0.649] \\
\hline $\mathrm{D}(\mathrm{DYY})(-5)$ & -0.0046 & 0.0167 & 0.2738 [0.787] \\
\hline $\mathrm{D}(\mathrm{DYY})_{(-6)}$ & -0.0157 & 0.0153 & $1.0248[0.321]$ \\
\hline $\mathrm{D}(\mathrm{DYY})_{(-7)}$ & -0.0392 & 0.0177 & $-2.2150[0.042]^{*}$ \\
\hline $\mathrm{D}(\mathrm{P})$ & -0.7718 & 0.2883 & $-2.6762[0.017]^{* *}$ \\
\hline $\mathrm{D}(\mathrm{P})_{(-1)}$ & 0.3387 & 0.2498 & -1.3558 [0.195] \\
\hline $\mathrm{D}(\mathrm{P})_{(-2)}$ & -0.0099 & 0.2601 & 0.0383 [0.969] \\
\hline $\mathrm{D}(\mathrm{P})_{(-3)}$ & 0.6512 & 0.3005 & $2.1670[0.046]^{* *}$ \\
\hline $\mathrm{D}(\mathrm{P})_{(-4)}$ & 0.7809 & 0.2947 & $2.6496[0.018]^{* *}$ \\
\hline D(Trend) & 0.0880 & 0.0277 & $3.1776[0.006]^{* * *}$ \\
\hline $\operatorname{ECM}(-1)$ & -0.5779 & 0.2508 & $-3.4992[0.003]^{* * *}$ \\
\hline
\end{tabular}

(1) Parantez içindeki rakamlar p-olasılık değerlerini göstermektedir.

(2) ${ }^{* * * * *}$ ve * sirasıyla \%1, \%5 ve \%10 düzeylerinde anlamlılıklarını gösterir.

Kısa dönem tahmin sonuçları diğer adıyla hata düzeltme modeli sonuçları Tablo 5 'te sunulmuştur. Bu sonuçlar incelendiğinde \%5 anlamlılık düzeyinde kısa dönemde DYY'nin pozitif(0.063) bir etkisi bulunmaktadır. Uzun dönemle paralel olarak P değişkeninin kısa dönemde de negatif (-0.771) bir etkisi bulunmuştur. Ayrıca hata düzeltme katsayısı [ECM(-1)] beklentilere uygun bir şekilde 0 ile 1 aralığında, negatif ve istatistiksel olarak anlamlı bulunmuştur. Hata düzeltme katsayısının negatif olması herhangi bir sapmanın tekrar dengeye yönelik hareketini ifade ederken 1'den küçük olması ise sistemin dengeli olmasını ifade eder (Bozdağlığlu, 2007: 222). Bu katsayı değeri (-0.57) kısa dönemde meydana gelecek bir şok ve beklenmedik etkilerin daha sonraki dönemde ne kadarının düzeltilebileceğini ifade etmektedir. Çalışmanın sonuçlarında yer alan hata düzeltme katsayısı değerine göre kısa dönemde ortaya çıkabilecek beklenmedik etkilerin devam eden dönemde \%57 oranında düzeleceğini göstermektedir. Yani kısa dönemdeki sorunun yaklaşık 2 dönem sonra düzelip uzun döneme uyumun sağlanabileceği ifade edilmektedir.

Bu sonuçların yanında modelin kararlılığı yani modeldeki yapısal kırılma, Brown vd. (1975) geliştirmiş oldukları CUSUM ve CUSUMSQ grafikleri üzerinden incelenmiştir. Bu grafiklerde geri dönüşlü hata terimlerinin kareleri kullanılmaktadır (Brown vd. 1975:149-155). Bu grafikler \%5 anlamlılık düzeyinde belirlenen kritik çizgiler yardımıyla yorumlanır. Eğer modelde belirlenen çizgiler arasında ise katsayıların kararlı olduğu ifade edilebilir. Tam tersi durum söz konusu ise belirlenen sınırların dışında yer alıyorsa katsayıların durağanlığını belirten boş(null, sıfır) hipotezi reddedilir (Akel ve Gazel, 2014: 36). 


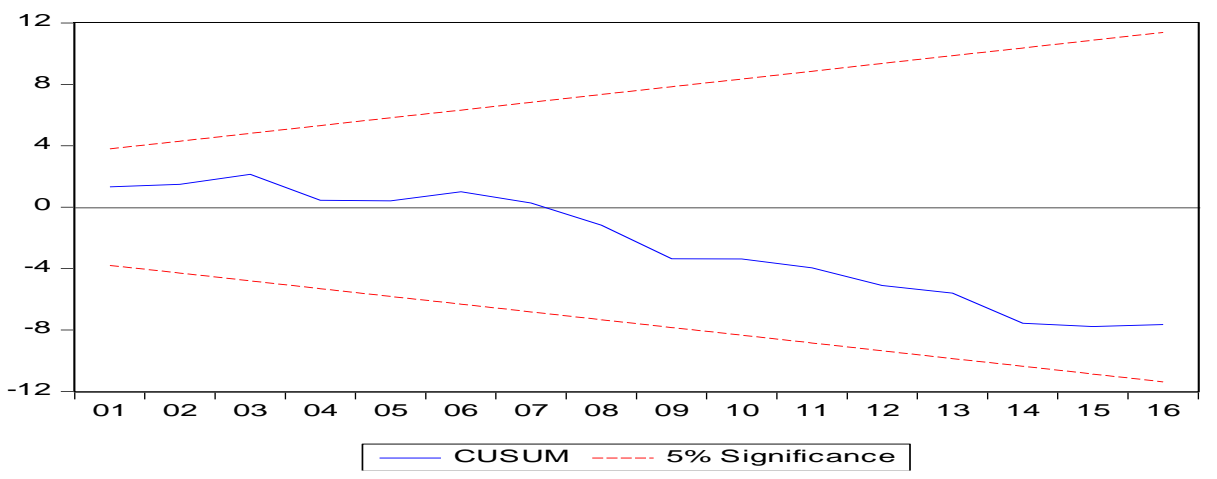

Şekil 1: CUSUM Grafiği

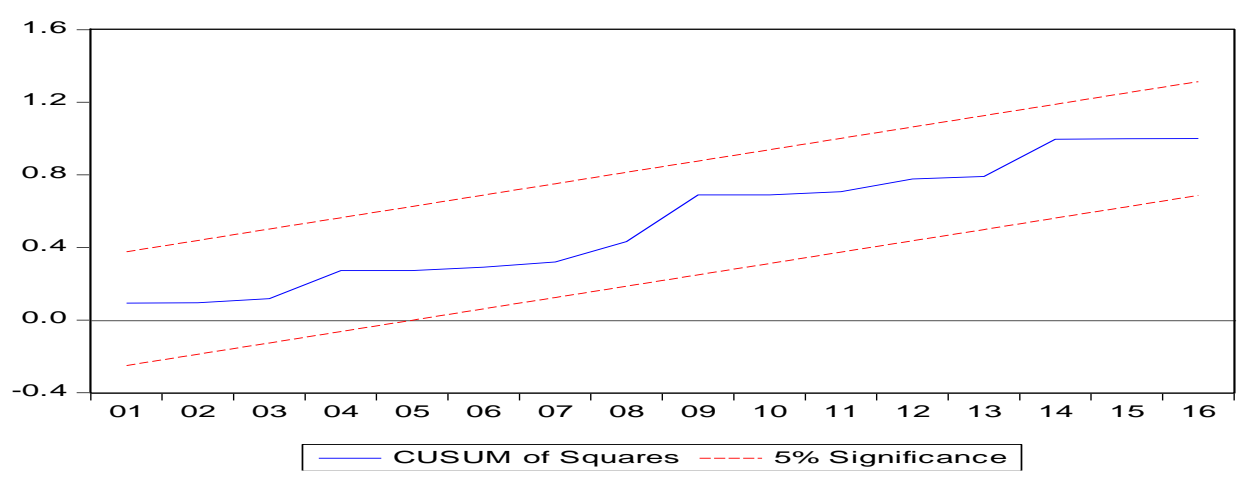

Şekil 2: CUSUMQ Grafiği

Yukarı yer alan grafikler (Şekil 1 ve Şekil 2) modelde herhangi bir yapısal kırılma olmadığını ifade etmektedir. Değişkenlerin istatistikleri kritik çizgiler arasında yer almakta, bu durum katsayıların istikrarlı olduğunu modelin farklı bir yapay değişken dâhil edilmeden tahmin edilebileceği sonucunu ortaya çıkarmıştır.

\section{Sonuç ve Öneriler}

DYY'nin vergi gelirleri üzerindeki etkisini kontrol etmek için, araştırmada bağımsız değişken olarak DYY ve istihdam edilen kişi başı GSYH, bağımlı değişken olarak vergi geliri kullanılmaktadır. ARDL ve hata düzeltme modeli, vergi gelir modelindeki uzun vadeli ve kısa vadeli ilişkiler için kullanılmaktadır. Sonuçlar, vergi gelir modelinde uzun vadeli ve kısa vadeli ilişkilerin bulunduğunu göstermektedir. DYY'nin vergi gelirleri üzerinde olumlu ve önemli bir etkisi vardır, bu nedenle DYY, devletin vergi gelirini yükseltmek suretiyle genel refahı arttırmaya yardımcı olur. İstihdam edilen kişi başına düşen GSYİH vergi gelirlerinin GSYİH içindeki payını hem kısa hem uzun dönemde negatif etkilemektedir. Bu açıdan bakıldığında Türk vergi sistemi de dolaylı vergilerin ağırlıkta olduğu bir yapıya sahiptir (Mutlu ve Çelen, 2012: 13). Bu yüzden DYY'nin Türkiye' deki vergi gelirlerini arttırıcı bir etkisi olduğu söylenebilir (Koşar ve Van, 2012; Balıkçığlu vd., 2016). Dünya Bankası ve Birleşmiş Milletler raporlarında (UNCTAD, 2003; UNCTAD, 2008) yer alan verilere göre Türkiye gibi gelişmekte olan ülkelere gelen DYY gelişmiş ülkelere göre daha düşüktür. Bu durum vergi gelirlerini olumsuz olarak etkilemektedir. Ayrıca literatürde Türkiye üzerine yapılan bazı çalışmalara (Sarısoy ve Koç, 2010; Bahtiyar, Karabacak ve Meçik, 2018) göre de Türkiye'nin 
DYY'den elde etmiş olduğu hasılat ya çok az ya da DYY vergi gelirleri arasında nedensellik ilişkisi olmadığı yönündedir.

Bundan dolayı devletin en önemli gelir kaynağı olan vergi gelirlerinin arttırılması için yatırımları arttırmak ve bunun için gerekli koşulların sağlanması gerekmektedir. DYY için yapılması gerekenlerden bazıları şu şekildedir; vergi muafiyeti (teşvikleri), hukuksal altyapı, yasal düzenlemeler, güvenlik vb. başlıklar sayılabilir. Uygun ortamın oluşması DYY miktarını arttıracak dolayısıyla ülke geliri büyük ölçüde artmış olacaktır. Ayrıca DYY için uygun şartları sağlayacak finansmanın bulunması kolaylaşacak ve Markusen' in (2001) bahsetmiş olduğu gibi DYY'nin refah sağlayıcı etkisi ev sahibi ülke için yüksek olacaktır

\section{Kaynakça}

Akel, V. ve Gazel, S. (2014). “Döviz Kurları ile BİST Sanayi Endeksi Arasındaki Eşbütünleşme İlişkisi: Bir ARDL Sınır Testi Yaklaşımı”. Erciyes Üniversitesi İktisadi ve İdari Bilimler Fakültesi Dergisi, (44), 23-41.

Aktan, C. C. (2009). “Arz-Yönlü İktisat Teorisi ve Haldun-Laffer Etkisi”. Ekonomi Bilimleri Dergisi, 1(2), 40-54.

Altintaş, H. (2008). “Türkiye'de Para Talebinin İstikrarı ve Sınır Testi Yaklaşımıyla Öngörülmesi: 1985-2006". Erciyes Üniversitesi İktisadi ve İdari Bilimler Dergisi, 30(30).

Andrejovska, A.,\& Pulikova, V. (2018). "TaxRevenues in the Context of Economic Determinants". Montenegrin Journal of Economics, 14(1), 133-141.

Bahtiyar, E., Karabacak, M. ve Meçik, O.(2018). AB Ülkeleri ve Türkiye'de Doğrudan Yabancı Yatırımlar ve Vergi Gelirleri İlişkisi: Panel Veri Analizi. İzmir International Congress on Economics and Administrative Sciences IZZCEAS 2018, 499-510.

Balıkçığlu, E., Dalgıç, B. and Fazlığlu, B. (2016). "Does Foreign Capital Increase Tax Revenue: The Turkish Case". International Journal of Economicsand Financial Issues, 6(2).

Basheer, M.,Ahmad, A., \& Hassan, S. (2019). “Impact of Economicand Financial Factors on Tax Revenue: Evidence From the Middle East Countries". Accounting, 5(2), 53-60.

Bond, E. and Samuelson, L. (1986). "Tax Holidays as Signals". American Economic Review, 76, 820-826.

Bozdağlığlu, E. Y. U. (2007). “Türkiye'nin İthalat ve İhracatının Eşbütünleşme Yöntemi ile Analizi (1990-2007)". İktisadi ve İdari Bilimler Fakültesi Dergisi, 9(3), 1-12.

Brander, J. andSpencer, B. (1987). "Foreign Direct Investment with Unemployment and Endogenous Taxes and Tariffs". Journal of International Economics, 22, 257-279.

Caves, R.E. (1971). "International Corporations: The Industrial Economics of Foreign Investment". Economica, 38, 1-27.

Dunning, J.H. (1993). MNEs, the Balance of Payments and the Structure of Trade. In: Dunning, J.H. (ed.). Multinational Enterprises and the Global Economy. Addison Wesley, Wokingham, UK and Reading, MA.

Durkaya, M. ve Ceylan, S. (2006). “Vergi Gelirleri ve Ekonomik Büyüme”, Maliye Dergisi, 150, 79-89. 
Eriçok, R. E. ve V. Yılancı (2013), “Eğitim Harcamaları ve Ekonomik Büyüme İlişkisi: Sınır Testi Yaklaşımı”, Bilgi Ekonomisi ve Yönetimi Dergisi, 8(1), 87-101.

Engle, R. F.,\&Granger, C. W. (1987). “Co-integration and Error Correction: Representation, Estimation, and Testing. Econometrica".Journal of theEconometricSociety, 251-276.

Granger, C. W. and Newbold, P. (1974). "Spurious Regressions in Econometrics". Journal of Econometrics, 2(2):111-120.

Gropp, R. andKostial, K. (2000). “The Disappearing Tax Base: Is Foreign Direct Investment Eroding Corporate Income Taxes?"ECB WorkingPaper No. 31. European Central Bank, Frankfurt.

Güler, A.ve Karaca, C. (2017, September). Türkiye'de Etkin Bir Vergi Sisteminin Kurulmasına İlişkin Politika Önerileri. In Proceedings of 2 nd International Conference on Scientific Cooperation for the Future in the Economics and Administrative Sciences (p. 165).

Güney, S. (2008).Türkiye için Nominal Döviz Kurunun Belirlenmesinde Net Uluslararası Rezerv Modelinin Geçerliliği: Sınır Testi Yaklaşımı. Gazi Üniversitesi Sosyal Bilimler Enstitüsü, (Yayımlanmamış Yüksek Lisans Tezi), Ankara, 2008.

Horstmann, I.J. and Markusen, J.R. (1992). “Endogenous Market Structures in International Trade". Journal of International Economics, 32, 109-129.

IMF 2006, Kenya, Uganda, and United Republic of Tanzania: SelectedIssues; IMF Country Report 353; December 1, 2006 p.11.

Jeza, M.,T., Hassen, A.,A. And Ramakrishna, G. (2016). The Relationship between FDI flows and Tax Revenues in Ethiopia: an Evidence based on ARDL Model with a Structural Break, International Conference on Ethiopian Economy, organizedby EEA during 21-23, July 2016, Addis Ababa, Ethiopia.

Keskin, N. (2008). Finansal Serbestleşme Sürecinde Uluslararası Sermaye Hareketleri ve Makroekonomik Etkileri: Türkiye Örneği. Dokuz Eylül Üniversitesi, Sosyal Bilimler Enstitüsü, (Yayımlanmamış Doktora Tezi), İzmir, 2008.

KimmGnangnon, S. (2017). "Impact of Foreign Direct Investment (FDI) Inflows on NonResource Tax and Corporate Tax Revenue". Economics Bulletin, 37(4), 2890-2904.

Kopits, G.F. (1976). “Intra-Firm Royalties Crossing Frontiers and Transfer-Pricing Behaviour". Economic Journal, 86, 781-805.

Koşar, N. ve Van, M.H. (2012). “Uluslararası Vergi Rekabetinin Doğrudan Yabancı Sermaye Yatırımları Üzerindeki Etkilerinin Türkiye Açısından Değerlendirilmesi".Yönetim ve Ekonomi Araştırmaları Dergisi, 18, 1-19.

Mahmood, H.,\&Chaudhary, A. R. (2013). "Impact of DYY on taxrevenue in Pakistan”. Pakistan Journal of Commerce andSocial Sciences, 7(1), 59-69.

Markusen, J.R. (1984). "Multinationals, Multi-Plant Economies, and the Gains fromTrade". Journal of International Economics, 16, 205-266.

Markusen, J.R. (1997). “Trade versus Investment Liberalisation”. NBER WorkingPaper No. 6231, Cambridge, MA. 
Markusen, J.R. (2001). “Contracts, Intellectual Property Rights, and Multinational Investment in DevelopingCountries". Journal of International Economics, 53, 189-204.

Markusen, J.R. (2002). Multinational Firms and the Theory of International Trade. MIT Press, Cambridge, MA.

Markusen, J.R.,Venables, A.J., Konan, D.E., andZhang, K.H. (1996)." A Unified Treatment of Horizontal Direct Investment, Vertical Direct Investment, and the Pattern of Trade in Goodsand Services". NBER WorkingPaper No. 5696, Cambridge, MA.

Mudambi, R. (1999). "Multinational Investment Attraction: Principle-Agent Considerations". International Journal of Economics of Business, 6, 65-79.

Mutlu, A. ve Çelen, M. (2012). “Dolaylı ve Dolaysız Vergilerin Türk Mali Sistemi İçerisindeki Yeri: Siyasal, Sosyal Ve Ekonomik Sonuçları". TÜSİAD Yayın No: TÜSİAD, 2012-10.

Nguyen, H. T. T.,Nguyen, M. H., \&Goenka, A. (2013). “How Does FDI Affect Corporate Tax Revenue of the Host Country?". Document De Recherche Epee, CentreD'etudes Des Politiques Economiques De L'universiteD'evry, RetrievedAugust, 10(2014), 13-03.

Okey, M. K. N. (2013). "Tax Revenue Effect of Foreign Direct Investment in West Africa". African Journal of Economic and Sustainable Development, 2(1), 1-22.

Pesaran, M. H.,Shin, Y., \& Smith, R. J. (2001). “Bounds Testing Approaches to the Analysis of Level Relationships". Journal of AppliedEconometrics, 16(3), 289-326.

Raff, H. ve Srinivasan, K. (1998). “Tax Incentives for Import-Substituting Foreign Investment: Does Signaling Play a Role?".Journal of PublicEconomics, 67, 167-193.

Sarısoy, İ., ve Koç, S. (2010). “Doğrudan Yabancı Sermaye Yatırımlarının Kurumlar Vergisi Gelirleri Üzerindeki Etkisinin Ekonometrik Analizi". Erciyes Üniversitesi İktisadi ve İdari Bilimler Fakültesi Dergisi, (36), 133-153.

Skeie, Ø. B. (2017). "International Differences in CorporateTaxation, Foreign Direct Investmentand Tax Revenues." OECD Economics Department WorkingPapers No. 1359

Şimşek, M. ve Kadılar, C. (2011). “Türkiye'nin İthalat Talebi Fonksiyonunun Sınır Testi Yaklaşımı ile Eşbütünleşme Analizi: 1970 - 2002”. Doğuş Üniversitesi Dergisi, 5 (1), 27-34.

Temiz, D. (2008). “Türkiye'de Vergi Gelirleri ve Ekonomik Büyüme İlişkisi: 1960-2006 Dönemi". 2. Ulusal İktisat Kongresi, 20-22.

UNCTAD (2003), World Investment Report 2003, FDI Policies for Development: National and International Perspectives, United Nations, New York andGeneva.

UNCTAD (2008), World Investment Report 2008, Transnational Corporations, and the Infrastructure Challenge, United Nations, New York and Geneva. 